The International Journal of Indian Psychology

ISSN 2348-5396 (e) | ISSN: 2349-3429 (p)

Volume 4, Issue 1, No. 75, DIP: 18.01.051/20160401

ISBN: 978-1-365-50727-4

http://www.ijip.in | October-December, 2016

\title{
Sustainable Behaviors and Happiness: An Optimistic Link
}

\author{
Gyanesh Kumar Tiwari ${ }^{1 *}$
}

\section{ABSTRACT}

The present study aimed to explicate the impacts of a set of positive behaviours i.e., sustainable behaviours in shaping the nature and extent of happiness of the graduate students. Two hundred undergraduate students with equal number of male and female served as the participants in the present study. Six components of sustainable behaviours and happiness of the participants were measured with the help of the two standardized psychometric tools. The results evinced that the male participants demonstrated higher mean scores on energy conservation behaviours, mobility and transportation, waste avoidance and social behaviours toward conservation components of sustainable behaviours as compared to their female counterparts. Contrarily, the females showed higher mean scores on consumerism and recycling components of the same measure as compared to the males. Overall, the male scored significantly higher on the sustainable behaviours as compared to the females. Likewise, the male participants also achieved higher mean score on the measure of happiness as compared to the females. All the dimensions of sustainable behaviours were positively correlated with happiness. In addition, all the dimensions of sustainable behaviours significantly predicted happiness of the participants. The results of the study have been discussed in the light of current theories of environment, sustainable behaviours and happiness. The results of the study have significant implications for the policy makers, administrators, researchers, environmentalists and the public at large. The future directions of research have been discussed. An attempt has also been made to raise some theoretical and practical issues which are not only pertinent to the academia of today but also carry practical implications for all human beings. It focuses the need of conceptual and methodological exchange among the relevant branches of knowledge.

Keywords: Sustainable behaviours, Happiness, Energy Conservation Behaviours, Waste Avoidance and Social Behaviors, Consumerism and Recycling.

The deterioration of the biosphere encompassing its three levels (atmosphere, soil, water) is the most serious concern of the day. Human behavior plays a pivotal role in the emergence and

\footnotetext{
${ }^{1}$ Assistant Professor, Department of Psychology, School of Humanities \& Social Sciences, Doctor Harisingh Gour Central University, Sagar, M. P., India

*Responding Author

(C) 2016 G Tiwari; licensee IJIP. This is an Open Access Research distributed under the terms of the Creative Commons Attribution License (http://creativecommons.org/licenses/by/2.0), which permits unrestricted use, distribution, and reproduction in any Medium, provided the original work is properly cited.
} 


\section{Sustainable Behaviors and Happiness: An Optimistic Link}

sustenance of environmental problems. Consumerism, waste and depredation of resources, contamination, egoistic and inequitable behaviors are major components of human behaviour which significantly shape and determine environmental quality. Sustainable behavior generally encompasses a series of actions intended at protecting both the physical and the social environments. It has been argued that consumerism, waste and depredation of resources, contamination, egoistic and inequitable behaviors, need to be replaced by sustainable behavior comprising a set of conscious and effective actions that result in the conservation of the sociophysical environment for present and future generations (Bonnes \& Bonaiuto, 2002). Sustainable behavior generally consists of a series of actions intended at protecting both the physical and the social environments (Corral-Verdugo et al., 2011).

The researchers have reported that sustainable behaviours include actions and behaviours which result into the conservation of the physical environment and protection of the interest of other individuals and groups. These behaviours also result in creating conditions giving way to an equitable access to the natural resources to those who need (Ehrlich \& Ehrlich, 2004). Such individuals are reported to be reasonable in their consumption of the resources making others accessible (De Young, 1996; Iwata, 2001) and demonstrate cooperative behaviours (Pol, 2002) and altruism (Schultz, 2001). The findings of these studies instigated a series of studies reporting that sustainable actions signify pro-ecological, frugal, altruistic and equitable behaviors (Iwata, 2001; Schultz, 2001). The conservation of natural resources (Thogersen, 2005), proenvironmental lobbying, reading and discussing about environmental problems, pro-ecological design, and family planning (Bandura, 2002; Kellert, Heerwagen \& Mador, 2008; Hsu, 2004; Suárez, 2000) are some of the other consequences of positive environmental behaviours.

The sustainable behaviours result in many sorts of positive reinforcement for their followers and help avoid negative consequences including both extrinsic and intrinsic motivations (Lehman \& Geller, 2004). Such consequences include social recognition and money although difficult to be used as strategies to encourage sustainable actions (Geller, 2002). Contrary to this, intrinsic consequences are the natural and automatic results of behavioral responses which are easier to mobilize the individuals for pro-environmental behaviors and effective in terms of longevity and intensity (Kasser, 2009). A popular psychological and intangible positive consequence of sustainable behaviours is happiness (Kasser, 2009). The sustainable behaviour patterns have been reported to promote a state of psychological restoration from unpleasant psychological states of stress (Hartig et al., 2001; Talbert, 2008). Practicing sustainable behaviors result into personal, collective and social consequences characterized by positive psychological states such as happiness and life satisfaction (Gardner \& Prugh, 2008).

Based on a large data from people living in OECD between 1975 and 1997, Di Tella and MacCulloch (2008) found happiness to be negatively affected by environmental degradation. In the same line, Welsch (2002) also reported negative impacts of urban air pollution on happiness.

(C) The International Journal of Indian Psychology, ISSN 2348-5396 (e)| ISSN: 2349-3429 (p) | 128 


\section{Sustainable Behaviors and Happiness: An Optimistic Link}

An increase in per capita water pollution had been found to be associated with a negative impact on both the happiness and life satisfaction in a study with cross-sectional data from 30 countries (Israel \& Levinson, 2003). The review indicated that psychological well-being, human functioning and performance are well integrated with the quality of life of the people. India is also facing many sorts of environmental problems so the study like this one is strongly needed to motivate the future researchers to plan further studies in helping the people understand the relationship of environment and psychology. The present research got insights from the conclusions of these studies and attempted to explicate the role of sustainable behaviours in shaping the nature and extent of general happiness of the graduate students. In the present study six dimensions of sustainable behaviours i. e., energy conservation behaviours, mobility and transportation, waste avoidance, consumerism, recycling and social behaviors toward conservation and happiness of the male and female graduate students will be measured. The measure objectives of the study were as follows:

1. To study the nature and extent of relationship between sustainable behaviours along with its components and happiness of the graduate students,

2. To understand the gender differences in sustainable behaviours of the graduate students,

3. To understand the gender differences in happiness of the graduate students,

4. To inquire into the predictive values of sustainable behaviours and its six components for happiness of the graduate students.

\section{METHODS AND PROCEDURE}

\section{Sample:}

Two hundred undergraduate students with equal number of male and female served as the participants in the present study whose sustainable behaviours and happiness were measured with the help of standardized psychological tools.

\section{Psychometric Tools:}

1. General Ecological Behaviour Scale: Developed and standardized by Kaiser (1998), General Ecological Behaviour Scale consists of sixty five items with five point Likert scale related to six components of sustainable behaviours i.e., energy conservation behaviours (14 items), mobility and transportation (14 items), waste avoidance (06 items), consumerism (13 items), recycling (05 items) and social behaviors toward conservation (13 items). This scale was translated into Hindi language first by two researchers followed by retranslation into English language by the researcher himself before using it as a tool.

2. General Happiness Scale: Lyubomirsky \& Lepper (1999) developed a 4-item scale designed to measure subjective happiness. Each of the item is completed by choosing one of 7 options finishing a given sentence fragment. This scale was translated into Hindi language first by two researchers followed by retranslation into English language by the researcher himself before using it as a tool. 


\section{Sustainable Behaviors and Happiness: An Optimistic Link}

\section{Procedure:}

After the objectives, tools of measurement and samples were selected, identified and prepared, the participants were approached and rapport was established. Before supplying the two scales and the start of the measurement, instructions were made understood to the participants. The whole sample was divided into ten groups of twenty participants for the sake of convenience of administration and control. The obtained data were scored, tabulated and statistically analyzed to compute mean, standard deviations (SDs), Pearson Product Moment method of correlation and regression analysis with the help of SPSS.

\section{RESULTS}

The results of the present study demonstrated that male showed statistically higher mean score on mobility and transportation $(\mathrm{M}=49.90, \mathrm{SD}=2.65)$, waste avoidance $(\mathrm{M}=18.41, \mathrm{SD}=1.45)$, and social behaviors toward conservation $(\mathrm{M}=44.14$, $\mathrm{SD}=2.55)$ as compared to the female participants $(\mathrm{M}=39.43, \mathrm{SD}=3.41),(\mathrm{M}=17.22, \mathrm{SD}=1.28),(\mathrm{M}=37.32, \mathrm{SD}=2.09)$. Contrarily, the female participants achieved higher mean scores on recycling $(\mathrm{M}=17.76, \mathrm{SD}=$ 1.22) as compared to their male counterparts $(M=12.30, S D=1.24)$. There were no significant difference among the mean scores of energy conservation behaviours and consumerism components of sustainable behaviours of the males and females. Overall, the male participants achieved higher mean score on sustainable behaviours $(\mathrm{M}=209.59, \mathrm{SD}=10.83)$ as compared to the females $(\mathrm{M}=197.41, \mathrm{SD}=11.60)$ (Table 1).

The scores on happiness showed that the male participants achieved higher mean score on happiness $(\mathrm{M}=21.86, \mathrm{SD}=1.43)$ as compared to the females $(\mathrm{M}=19.30, \mathrm{SD}=1.00)$. These mean scores were also statistically significant $(\mathrm{t}=14.74 \mathrm{df}=99, p=.000)$.

Table 1: The mean, SDs and t-test values of the scores of energy conservation behaviours, mobility and transportation, waste avoidance, consumerism, recycling and social behaviors toward conservation components of sustainable behaviours of males and females

\begin{tabular}{|c|c|c|c|c|c|c|c|c|}
\hline S. No. & Dimensions of GEB & Gender & $\mathbf{M}$ & SD & t & df & $p$ & $\mathbf{N}$ \\
\hline \multirow{2}{*}{1.} & \multirow{2}{*}{ Energy conservation behaviours } & M & 42.87 & 3.87 & \multirow{2}{*}{1.21} & \multirow{2}{*}{99} & \multirow{2}{*}{.230} & 100 \\
\hline & & $\mathrm{F}$ & 42.17 & 4.27 & & & & 100 \\
\hline \multirow{2}{*}{2.} & \multirow{2}{*}{ Mobility and transportation } & M & 48.90 & 2.65 & \multirow{2}{*}{20.65} & \multirow{2}{*}{99} & \multirow{2}{*}{.000} & 100 \\
\hline & & $\mathrm{F}$ & 39.43 & 3.41 & & & & 100 \\
\hline \multirow{2}{*}{3.} & \multirow{2}{*}{ Waste avoidance } & $\mathrm{M}$ & 18.41 & 1.45 & \multirow{2}{*}{6.33} & \multirow{2}{*}{99} & .000 & 100 \\
\hline & & $\mathrm{F}$ & 17.22 & 1.28 & & & & 100 \\
\hline \multirow{2}{*}{4.} & \multirow{2}{*}{ Consumerism } & $\mathrm{M}$ & 42.97 & 2.34 & \multirow{2}{*}{1.61} & \multirow{2}{*}{99} & \multirow{2}{*}{.110} & 100 \\
\hline & & $\mathrm{F}$ & 43.51 & 2.29 & & & & 100 \\
\hline \multirow{2}{*}{5.} & \multirow{2}{*}{ Recycling } & $\mathrm{M}$ & 12.30 & 1.24 & \multirow{2}{*}{32.65} & \multirow{2}{*}{99} & \multirow{2}{*}{.000} & 100 \\
\hline & & $\mathrm{F}$ & 17.76 & 1.22 & & & & 100 \\
\hline \multirow{2}{*}{6.} & \multirow{2}{*}{ Social behaviors toward conservation } & $\mathrm{M}$ & 44.14 & 2.55 & \multirow{2}{*}{22.24} & \multirow{2}{*}{99} & \multirow{2}{*}{.000} & 100 \\
\hline & & $\mathrm{F}$ & 37.32 & 2.09 & & & & 100 \\
\hline \multirow{2}{*}{7.} & \multirow{2}{*}{ Sustainable Behaviours } & M & 209.59 & 10.83 & \multirow{2}{*}{7.85} & \multirow{2}{*}{99} & \multirow{2}{*}{.000} & 100 \\
\hline & & $\mathrm{F}$ & 197.41 & 11.60 & & & & 100 \\
\hline
\end{tabular}

(c) The International Journal of Indian Psychology, ISSN 2348-5396 (e)| ISSN: 2349-3429 (p) | 130 


\section{Sustainable Behaviors and Happiness: An Optimistic Link}

The correlation coefficients were computed with the help of Pearson Product Moment method for the scores of energy conservation behaviours $(\mathrm{r}=.555, p=.000, \mathrm{r}=.867, p=.000)$, mobility and transportation $(\mathrm{r}=.652, p=.000, \mathrm{r}=.668, p=.000)$, waste avoidance $(\mathrm{r}=.806, p=.000, \mathrm{r}=$ .776, $p=.000)$, consumerism $(\mathrm{r}=.723, p=.000, \mathrm{r}=.859, p=.000)$, recycling $(\mathrm{r}=.933, p=$ $.000, \mathrm{r}=.873, p=.000)$ and social behaviors toward conservation $(\mathrm{r}=.561, p=.000, \mathrm{r}=.534, p$ $=.000$ ) components of sustainable behaviours and the their corresponding scores on happiness which evinced statistical significance for all the male and female participants (Table 2). The results explicitly demonstrated the big impacts of sustainable behaviours which were observed in the determination levels of happiness of the participants (Table 2).

The regression analysis showed that $22.40 \%, 30.80 \%, 32.50 \%, 35.00 \%, 25.20 \%$ and $38.00 \%$ of happiness of males and 26.70\%, 35.20\%, 34.60\%, 30.20\%, 37.80\%, and 26.20\% of happiness of females were predicted by their energy conservation behaviours, mobility and transportation, waste avoidance, consumerism, recycling and social behaviors toward conservation components of sustainable behaviours, respectively. When the scores of sustainable behaviours and happiness of were pooled, it predicted $35.30 \%$ happiness of the males and $34.70 \%$ happiness of the females. The predictive role of sustainable behaviours comprising energy conservation behaviours, mobility and transportation, waste avoidance, consumerism, recycling and social behaviors toward conservation is evident in the percentage it contributed to determine the nature and extent of happiness of the participants. Cumulative predictive value of sustainable behaviours measure was surprising and insightful.

Table 2: The correlations coefficients among the scores of energy conservation behaviours, mobility and transportation, waste avoidance, consumerism, recycling and social behaviors toward conservation components of sustainable behaviours and the scores of happiness of the participants

\begin{tabular}{|c|c|c|c|c|c|}
\hline S. No. & Dimensions of GSB & Happiness & Gender & $\mathbf{r}$ & $p$ \\
\hline \multirow{2}{*}{1.} & \multirow{2}{*}{$\begin{array}{l}\text { Energy conservation } \\
\text { behaviours }\end{array}$} & \multirow{2}{*}{ Happiness } & Male-Male & .555 & .000 \\
\hline & & & Female-Female & .867 & .000 \\
\hline \multirow{2}{*}{2.} & \multirow{2}{*}{$\begin{array}{l}\text { Mobility and } \\
\text { transportation }\end{array}$} & \multirow{2}{*}{ Happiness } & Male-Male & .652 & .000 \\
\hline & & & Female-Female & .668 & .000 \\
\hline \multirow{2}{*}{3.} & \multirow{2}{*}{ Waste avoidance } & \multirow{2}{*}{ Happiness } & Male-Male & .806 & .000 \\
\hline & & & Female-Female & .776 & .000 \\
\hline \multirow{2}{*}{4.} & \multirow{2}{*}{ Consumerism } & \multirow{2}{*}{ Happiness } & Male-Male & .723 & .000 \\
\hline & & & Female-Female & .859 & .000 \\
\hline \multirow{2}{*}{5.} & \multirow{2}{*}{ Recycling } & \multirow{2}{*}{ Happiness } & Male-Male & .933 & .000 \\
\hline & & & Female-Female & .873 & .000 \\
\hline \multirow{2}{*}{6.} & \multirow{2}{*}{$\begin{array}{l}\text { Social behaviors toward } \\
\text { conservation }\end{array}$} & \multirow{2}{*}{ Happiness } & Male-Male & .561 & .000 \\
\hline & & & Female-Female & .534 & .000 \\
\hline
\end{tabular}




\section{DISCUSSION}

The results of the present study evinced that the various components of sustainable behaviours significantly shaped the nature and extent of the happiness of the male and female participants. The results showed that male scored statistically higher mean score on mobility and transportation, waste avoidance, and social behaviors toward conservation as compared to the female participants whereas the female participants achieved higher mean scores on recycling as compared to their male counterparts. There were no significant difference among the mean scores of energy conservation behaviours and consumerism components of sustainable behaviours of the male and females. Overall, the male participants achieved higher mean score on sustainable behaviours as compared to the females.

The scores on happiness showed that the male participants achieved higher mean score on sustainable behaviours as compared to the females. These mean scores were statistically significant. The correlation coefficients were significant for the scores of energy conservation behaviours, mobility and transportation, waste avoidance, consumerism, recycling and social behaviors toward conservation components of sustainable behaviours and the their corresponding scores on happiness for all the male and female participants. In addition, the regression analysis showed that happiness of males and females were predicted by energy conservation behaviours, mobility and transportation, waste avoidance, consumerism, recycling and social behaviors toward conservation components of sustainable behaviours.

The results of the study find support from the previous studies which have identified many antecedents like environmental knowledge, pro-ecological attitudes, conservationist motives, personal norms, ecological beliefs and values, affinity towards diversity etc. (Bamberg \& Möser, 2007; Corral-Verdugo, Bonnes, Carrus, Frias, Tapia \& Fraijo, 2009) and extrinsic and intrinsic consequences of sustainable behaviours (Bechtel \& Corral-Verdugo, 2010) in explaining various dimensions of human behaviours. Physical-environmental (access to fresh water, refuse management, control of green house gas), social (justice, living conditions, low corruption levels, access to education), political/institutional (infrastructure, science participation, low corruption levels), and economic (economic activity ratio, income distribution, employment) areas are some other major consequences of sustainable behaviours (Flavin, 2002; Gouveia, 2002; Gardner, 2002).

The recent researchers have shown that good intellectual, moral, social and spiritual development, effective self-development, life satisfaction, personal well-being, mental health, national character, intrinsic motivation, and psychological restoration are shaped by psychological consequences of sustainable behaviours of the individuals (Hartig, Kaiser \& Bowler, 2001; Iwata, 2001; Kasser, 2009). Due to the increased importance of these researches around the globe, the nations of the world have advocated Happy Planet Index (HPI) to assess ecological efficiency to achieve long and happy life (Marks et al., 2006). In consonance with that 


\section{Sustainable Behaviors and Happiness: An Optimistic Link}

some European countries, Australia and Bhutan have established their goals achieving the subjective wellbeing (happiness) of their inhabitants as a national and sustainable policy goal. The Kingdom of Bhutan has its official goal is no longer economic growth, assessed as Gross Domestic Products (GDP) but “Gross National Happiness (GNH)” (Gardner \& Prugh, 2008).

The researchers have put forth two theories to explain the mechanisms of sustainable behaviors through which these result into the positive psychological consequences. According to evolutionary psychology, the humans gain happiness because their brains evolved to experience positive emotional experiences (Haviland-Jones, Rosario, Wilson, \& McGuire, 2005) which are associated with pursuing one's and other's benefits via either egoistic or altruistic strategies. On the other hand, behaviouristic theorists explain the impact of sustainable behaviours on human well-being through positive and negative consequences.

\section{CONCLUSIONS}

The results of the present study unequivocally posited that sustainable behaviours have significant role in shaping an individual's happiness. Among others, gender differences are there in sustainable behaviours and their consequences of happiness of the individuals. The six components of sustainable behaviours are positively correlated to the happiness of the participants. Overall, the measure of sustainable behaviours significantly predicted happiness of the participants.

\section{IMPLICATIONS AND FUTURE DIRECTIONS}

It is evident on the basis of the results of the present study that the interdisciplinary approach combining the knowledge of biological, socio-psychological, anthropological and many more etc. is needed to unearth the intricacies of environment, human interactions and functioning for sustainable development, positive development, ecological sustenance, resolving conflicts of local and global nature, policy framing and equitable distribution of resources. Lastly, it has a good potential to help people striving the pursuit of understanding and knowledge. Future researchers should exert greater efforts to unearth significant impacts of sustainable behaviours on human functioning and performance through qualitative and mixed methods studies. Future researchers should also focus the mode of interactions among sustainable behaviours and psychological variables such as self-esteem (Tiwari, 2014, Tiwari \& Kumar, 2014), body image (Jain \& Tiwari, 2016a; Jain \& Tiwari, 2016b) and forgiveness (Mudgal \& Tiwari, 2015). The sustainable behaviours might also be associated with emotional intelligence and academic achievement (Tiwari, 2016a), mental health and academic achievement (Gujare \& Tiwari, 2016), health habits and mental health (Tiwari, 2016b). This will lead to develop a more empiricallyoriented and eclectic approach to understand the interactions and inter-relations of environment and human behaviours. 


\section{Sustainable Behaviors and Happiness: An Optimistic Link}

\section{Acknowledgments}

The author appreciates all those who participated in the study and helped to facilitate the research process.

\section{Conflict of Interests}

The author declared no conflict of interests.

\section{REFERENCES}

Bamberg, S. \& Moser, G. (2007). Twenty years after Hines, Hungerford, and Tomera: A new meta-analysis of psycho-social determinants of pro-environmental behavior. Journal of Environmental Psychology, 27, 14-25.

Bandura, A. (2002). Environmental sustainability by socio-cognitive deceleration of population growth. En P. Schmuck \& P.W. Schultz (Eds.), Psychology of Sustainable Development. Norwell, Massachusetts: Kluwer.

Bechtel, R.B., \& Corral-Verdugo, V. (2010). Happiness and sustainable behavior. In V. CorralVerdugo, C. García, \& M. Frías (Eds.), Psychological Approaches to Sustainability. New York: Nova Science Publishers.

Bonnes, M., \& Bonaiuto, M. (2002). Environmental psychology: from spatial-physical environment to sustainable development. In R.B. Bechtel \& A. Churchman (Eds.), Handbook of Environmental Psychology (pp. 28-54). New York: Wiley.

Corral-Verdugo, V., Bonnes, M., Tapia, C., Fraijo, B., Frías, M., \& Carrus, G. (2009). Correlates of pro-sustainability orientation: the Affinity Towards Diversity. Journal of Environmental Psychology, 29, 34-43.

Corral-Verdugo, V., Mireles-Acosta, J., Tapia-Fonllem, C., \& Fraijo-Sing, B. (2011). Happiness as correlate of sustainable behavior: a study of pro-ecological, frugal, equitable and altruistic actions that promote subjective well-being. Human Ecology Review, 18(2), 95104.

De Young, R. (1996). Some psychological aspects of a reduced consumption lifestyle: The role of intrinsic atisfaction and competence motivation. Environment \& Behavior, 28, 358-409.

Di Tella, R., \& MacCulloch, J. R. (2008). Gross national happiness as an answer to the Easterlin Paradox? Journal of Development Economics, 86(1), 22-42.

Ehrlich, P. \& Ehrlich, A. (2004). One with Niniveh. Politics, Consumption and the Human Future. Washington, DC: Shearwater Books.

Flavin, C. (2002). Preface. En L. Starke (Ed.), State of the World 2002. A World Watch Institute Report on the Progress toward a Sustainable Society. Nueva York: W.W. Norton.

Gardner, G. \& Prugh, T. (2008). Seeding the sustainable economy. In Starke, L. (Ed.), State of the World. New York, W. W. Norton \& Company.

Gardner, G. (2002). The challenge for Johannesburg: creating a more secure world. En L. Starke (Ed.), State of the World 2002. A World Watch Institute Report on the Progress toward a Sustainable Society. Nueva York: W.W. Norton.

Geller, E.S. (2002). The challenge of increasing pro-environment behavior. In R. B. Bechtel \& A. Churchman (Eds.), Handbook of Environmental Psychology. New York: Wiley. 


\section{Sustainable Behaviors and Happiness: An Optimistic Link}

Gouveia, V. (2002). Self, culture and sustainable development. In P. Schmuck \& P.W. Schultz (Eds.), Psychology of Sustainable Development. Norwell, Massachusetts: Kluwer.

Gujare, S. K. \& Tiwari, G. K. (2016). Mental health symptoms predict academic achievement of the female students. The International Journal of Indian Psychology, Volume 4, Issue 1, No.76, 93-111. DIP: 18.01.006/20160476.

Hartig, T., Kaiser, F. \& Bowler, P. (2001). Psychological restoration in nature as a positive motivation for ecological behavior. Environment \& Behavior, 33, 590-607.

Haviland-Jones, J., Rosario, H., Wilson, P., \& McGuire, T. (2005). An environmental approach to positive emotion: flowers. Evolutionary Psychology, 3, 104-132.

Hsu, S.J. (2004). The effects of an environmental education program on responsible environmental behavior and associated environmental literacy variables in Taiwanese college students. Journal of Environmental Education, 35, 37-48.

Israel, D., \& Levinson, A. (2003). Examining the relationship between household satisfaction and pollution. Mimeo, Indiana State University.

Iwata, O. (2001). Attitudinal determinants of environmentally responsible behavior. Social Behavior and Personality, 29, 183-190.

Jain, P., \& Tiwari, G. K. (2016). Body image satisfaction and Life Satisfaction in HIV/AIDS patients. The International Journal of Indian Psychology, Volume 3, Issue 2, No.1, 81-90. DIP: 18.01.011/20160302.

Jain, P., \& Tiwari, G. K. (2016b). Positive body image and general health: A Mixed Methods Study. The International Journal of Indian Psychology, Volume 4, Issue 1, No. 76, 33-51. DIP: $18.01 .003 / 20160476$.

Kaiser, F. (1998). A general measure of ecological behavior. Journal of Applied Social Psychology, 28, 395-442.

Kasser, T. (2009). Psychological need satisfaction, personal wellbeing, and ecological sustainability. Ecopsychology, 1, 175-180.

Kellert, S.R., Heerwagen, J. \& Mador, M. (2008) (Eds.). Biophilic design: the theory, science and practice of bringing buildings to life. New York: Wiley.

Lehman, P.H. \& Geller, S. (2004). Behavior analysis and environmental protection: accomplishments and potential for more. Behavior and Social Issues, 13, 13-32.

Lyubomirsky, S. \& Lepper, H. S. (1999). A measure of subjective happiness: Preliminary reliability and construct validation. Social Indicators Research, 46, 137-155.

Marks, N., Simms, A., Thompson, S. \& Abdallah, S. (2006). The Happy Planet Index: an index of human well-being and environmental impact. Londres: New Economics Foundation and Friends of Earth.

Mudgal, S., \& Tiwari, G. K. (2015). Self-Forgiveness and Life Satisfaction in People Living with HIV/AIDS. The International Journal of Indian Psychology, Volume 3, Issue 1, No.10, 101-108. DIP: C03175V3I12015.

Pol, E. (2002a). The theoretical background of the City-Identity-Sustainability Network. Environment \& Behavior, 34, 8-25. 


\section{Sustainable Behaviors and Happiness: An Optimistic Link}

Schultz, P.W. (2001). The structure of environmental concern. Concern for self, other people, and the biosphere. Journal of Environmental Psychology, 21, 327-339.

Suárez, E. (2000). Problemas ambientales y soluciones conductuales [Environmental problems and behavioral Solutions]. In J.I. Aragonés \& M. Amérigo (Eds.), Psicología Ambiental. Madrid: Ediciones Pirámide

Talbert, J. (2008). Redefining progress. En Starke, L. (Ed.), State of the World. New York, W. W. Norton \& Company.

Thogersen, J. (2005). How may consumer policy empower consumers for sustainable lifestyles? Journal of Consumer Policy, 28, 143-177.

Tiwari, G. K. (2014). Body image satisfaction enhances self-esteem. Vaichariki, IV (4), 7-11.

Tiwari, G. K. (2016a). Mediating role of emotional intelligence in academic achievement of the graduate students. The International Journal of Indian Psychology, Volume 4, Issue 1, No.74, 49-59. DIP: 18.01.026/20160401.

Tiwari, G. K. (2016b). Yoga and mental health: An Underexplored relationship. The International Journal of Indian Psychology, Volume 4, Issue 1, No. 76, 19-31. DIP:18.01.002/20160476.

Tiwari, G. K., \& Kumar. S. (2015). Psychology of body image: A review. Shodh Prerak, 5 (1), 1- 9.

Welsch, H. (2002). Preferences over prosperity and pollution: environment valuation based on happiness surveys. Kyklos, 55(4), 473-494.

How to cite this article: G Tiwari (2016), Sustainable Behaviors and Happiness: An Optimistic Link, International Journal of Indian Psychology, Volume 3, Issue 4, No. 75, ISSN:2348-5396 (e), ISSN:2349-3429 (p), DIP:18.01.051/20160304, ISBN:978-1-365-50727-4 